\title{
Determination of the Sampler Type and Rainfall Effect on the Deposition Fluxes of the Polychlorinated Biphenyls
}

\author{
Askin Birgül and Yücel Tasdemir \\ Department of Environmental Engineering, Engineering and Architecture Faculty, Uludag University, Gorukle 16059, Bursa, Turkey \\ Correspondence should be addressed to Yücel Tasdemir, tasdemir@uludag.edu.tr
}

Received 19 October 2011; Accepted 7 December 2011

Academic Editors: G. O. Thomas and I. C. Ziomas

Copyright () 2012 A. Birgül and Y. Tasdemir. This is an open access article distributed under the Creative Commons Attribution License, which permits unrestricted use, distribution, and reproduction in any medium, provided the original work is properly cited.

\begin{abstract}
Atmospheric concentration and deposition samples were collected between June 2008 and June 2009 in an urban sampling site Yavuzselim, Turkey. Eighty-three polychlorinated biphenyl (PCB) congeners were targeted in the collected samples. It was found that $90 \%$ of the total PCB concentration was in the gas phase. Deposition samples were collected by a wet-dry deposition sampler (WDDS) and a bulk deposition sampler (BDS). Average total deposition fluxes measured with the BDS in dry periods was $5500 \pm$ $2400 \mathrm{pg} /\left(\mathrm{m}^{2}\right.$ day); average dry deposition fluxes measured by the WDDS in the same period were $6400 \pm 3300 \mathrm{pg} /\left(\mathrm{m}^{2} \mathrm{day}\right) . \mathrm{The}$ results indicated that the sampler type affected the measured flux values. Bulk deposition samples were also collected in rainy periods by using the BDS and the average flux value was $8700 \pm 3100 \mathrm{pg} /\left(\mathrm{m}^{2}\right.$ day $)$. The measured flux values were lower than the values reported for the urban and industrial areas. Dry deposition velocities for the WDDS and BDS samples were calculated $0.48 \pm 0.35 \mathrm{~cm} / \mathrm{s}$ and $0.13 \pm 0.15 \mathrm{~cm} / \mathrm{s}$, respectively.
\end{abstract}

\section{Introduction}

Their widespread use and properties have led PCBs to become globally distributed. Since production began in the 1930s, approximately 1.3 million tonnes of PCB have been manufactured and used in numerous applications, for example, as coolants and insulating fluids for transformers and capacitors, stabilizing additives in PVC coatings, pesticide extenders, cutting oils, flame retardants, hydraulic fluids, sealants, adhesives, wood floor finishes, carbonless copy paper, and paints [1,2].

PCBs may enter the atmosphere from a variety of diffuse sources, such as leakage of PCB-containing electrical installations (capacitors and transformers) that are still in use or stored at landfills, combustion of municipal and industrial wastes, or volatilization from contaminated buildings $[3,4]$. The food chain is the main source of human exposure to PCBs.

Urban and industrial areas are major sources of atmospheric PCBs to surrounding regions [5]. Atmospheric transport from major urban industrial areas can lead to a significant PCB loading to neighbouring terrestrial [6] and aquatic ecosystems [7], by diffusive air-water exchange, airvegetation exchange, wet deposition (rain-snow), and dry particle deposition. Once delivered, PCBs may be remobilized to the regional atmosphere by air-surface exchange processes $[8,9]$.

Atmospheric deposition is an important source of organic and inorganic contamination, consequently many studies have been performed by researchers in recent years to estimate the deposition values [10-13]. Various techniques such as Teflon surfaces, petri plates, water surfaces, and greased surfaces have been applied to determine atmospheric dry deposition fluxes of semivolatile organic compounds (SVOCs) [14-17]. Bulk deposition is achieved with a sampler which is always open to the atmosphere, thus wet-and-dry deposition takes place simultaneously [13].

Bursa $\left(40^{\circ} 10^{\prime} 58.17^{\prime \prime} \mathrm{N}, 29^{\circ} 4^{\prime} 6.32^{\prime \prime} \mathrm{E}\right)$ is the 4 th biggest city of Turkey located in the northwest of Marmara region with a population of 2.5 million people. It is an important transportation route and many industrial districts have been established in Bursa. PCBs have been measured in different environmental compartments around the world, but measurements in air are limited in Turkey. In order 
TABLE 1: Measured meteorological data during the sampling period.

\begin{tabular}{|c|c|c|c|c|c|c|}
\hline Number & Sampling period & Avg. temperature $\left({ }^{\circ} \mathrm{C}\right)$ & Avg. wind speed $(\mathrm{m} / \mathrm{s})$ & $\begin{array}{l}\text { Dominant wind } \\
\text { direction }\end{array}$ & Avg. humidity (\%) & $\begin{array}{c}\text { Rain } \\
\text { volume }(L) \\
\end{array}$ \\
\hline 1 & $11.06-18.06 .2008$ & $24 \pm 4$ & $0.9 \pm 1.0$ & WNW & $48 \pm 13$ & 0 \\
\hline 2 & $18.06-30.06 .2008$ & $27 \pm 4$ & $1.6 \pm 1.0$ & $\mathrm{NE}$ & $47 \pm 13$ & 0 \\
\hline 3 & $30.06-16.07 .2008$ & $26 \pm 4$ & $1.7 \pm 1.0$ & $\mathrm{~N}$ & $44 \pm 11$ & 0 \\
\hline 4 & $16.07-01.08 .2008$ & $25 \pm 4$ & $1.5 \pm 1.1$ & WNW & $54 \pm 14$ & 0 \\
\hline 5 & $01.08-15.08 .2008$ & $26 \pm 4$ & $1.7 \pm 1.0$ & ENE & $48 \pm 11$ & 0 \\
\hline 6 & $15.08-01.09 .2008$ & $27 \pm 4$ & $1.5 \pm 1.1$ & NE & $55 \pm 13$ & 0 \\
\hline 7 & 01.09-16.09.2008 & $24 \pm 4$ & $1.2 \pm 0.9$ & WNW & $53 \pm 13$ & 0.4 \\
\hline 8 & 16.09-16.10.2008 & $17 \pm 4$ & $0.9 \pm 1.1$ & WNW & $72 \pm 15$ & 7 \\
\hline 9 & $16.10-03.11 .2008$ & $16 \pm 3$ & $0.6 \pm 0.7$ & $\mathrm{NE}$ & $72 \pm 12$ & 0 \\
\hline 10 & 03.11-17.11.2008 & $14 \pm 3$ & $0.7 \pm 0.7$ & WNW & $81 \pm 10$ & 0.25 \\
\hline 11 & $17.11-01.12 .2008$ & $12 \pm 5$ & $2.3 \pm 2.6$ & SE & $69 \pm 17$ & 13.4 \\
\hline 12 & $01.12-16.12 .2008$ & $11 \pm 5$ & $1.4 \pm 1.1$ & $\mathrm{E}$ & $64 \pm 13$ & 0.28 \\
\hline 13 & $16.12-02.01 .2009$ & $5 \pm 4$ & $1.3 \pm 1.0$ & ENE & $77 \pm 9$ & 10.9 \\
\hline 14 & 02.01-17.01.2009 & $5 \pm 3$ & $1.3 \pm 0.9$ & $\mathrm{E}$ & $68 \pm 13$ & 16.2 \\
\hline 15 & $17.01-02.02 .2009$ & $10 \pm 5$ & $1.5 \pm 1.7$ & ENE & $66 \pm 14$ & 1.9 \\
\hline 16 & 02.02-17.02.2009 & $10 \pm 5$ & $1.8 \pm 1.8$ & WNW & $71 \pm 17$ & 19.5 \\
\hline 17 & $17.02-02.03 .2009$ & $5 \pm 3$ & $1.2 \pm 1.0$ & ENE & $76 \pm 10$ & 4 \\
\hline 18 & $02.03-16.03 .2009$ & $10 \pm 5$ & $1.9 \pm 2.0$ & WNW & $71 \pm 17$ & 10 \\
\hline 19 & $16.03-01.04 .2009$ & $9 \pm 5$ & $1.5 \pm 1.6$ & WNW & $66 \pm 16$ & 7 \\
\hline 20 & 01.04-17.04.2009 & $12 \pm 4$ & $1.1 \pm 0.9$ & WNW & $72 \pm 18$ & 1 \\
\hline 21 & $17.04-01.05 .2009$ & $14 \pm 5$ & $1.1 \pm 1.0$ & WNW & $67 \pm 15$ & 0.6 \\
\hline 22 & 01.05-16.05.2009 & $17 \pm 4$ & $1.1 \pm 1.1$ & WNW & $62 \pm 17$ & 0 \\
\hline 23 & $16.05-01.06 .2009$ & $20 \pm 4$ & $1.2 \pm 1.0$ & WNW & $57 \pm 15$ & 0 \\
\hline 24 & 01.06-16.06.2009 & $24 \pm 4$ & $1.3 \pm 1.1$ & WNW & $57 \pm 16$ & 0 \\
\hline
\end{tabular}

to assess this, potential of priority organic pollutants, gasparticle concentrations, temporal changes of dry and bulk deposition fluxes, and dry and bulk deposition velocities of these compounds were determined in urban air of Bursa, Turkey. This paper reports some of that work, focussing on a comparison of deposition samplers and derivation of deposition flux information.

\section{Materials and Methods}

2.1. Sampling Program. Thirty-four ambient air samples and 23 dry deposition and bulk deposition samples were collected from Yavuzselim (YS) sampling site between June 2008 and June 2009, in order to determine dry deposition and bulk deposition fluxes associated with atmospheric concentrations of PCBs.

YS was a residential site $\left(40^{\circ} 11^{\prime} 48.40^{\prime \prime} \mathrm{N}-29^{\circ} 5^{\prime} 46.80^{\prime \prime} \mathrm{E}\right)$ and located about $500 \mathrm{~m}$ away from the nearest major road. The sampling site was within the boundaries of Yildirım Municipality and the samplers were placed on the roof of a 3 -storey building. The YS sampling site was surrounded by residences and small workplaces and in this region natural gas and coal were mainly used as a fuel.

At the sampling site, one high volume air sampler (HVAS) (glass fibre filter (GFF) of $90 \mathrm{~mm}$ outer diameter (o.d.) and pore size of $1.6 \mu \mathrm{m}$, polyurethane foam (PUF) plug $50 \mathrm{~mm}$ high $\times 65 \mathrm{~mm}$ length (o.d) and density of $0.0225 \mathrm{~g} / \mathrm{cm}^{3}$, GPS 11, Thermo Andersen Inc., USA) and one wet and dry deposition sampler (WDDS) (each sampling part $40 \times 40 \mathrm{~cm}\left(0.16 \mathrm{~m}^{2}\right)$ and a depth of $70 \mathrm{~cm}$, TYN 400, Teknosem, Turkey) were deployed at the sampling site.

The HVAS was calibrated using a standardized orifice manometer kit (Thermo Andersen Inc., USA) based on the manufacturers requirements for calibration. The mean flow rate and the sampling volume for each sample were about $0.20 \mathrm{~m}^{3} / \mathrm{min}$ and $260 \mathrm{~m}^{3}$, respectively. The flow rates were checked before and after sampling by calibrated flow meters. Both gaseous and particulate phase PCBs were collected over four seasons, namely, from June 2008 to June 2009. There was a meteorological station in the sampling site in order to provide the meteorological data (Davis Vantage Pro2, Davis Instruments Corp., USA). The meteorological data recorded during the sampling period are summarized in Table 1.

2.2. Sample Collection. Ambient air samples were collected by means of the HVAS when there was no rainfall. Deposition samples (both dry and wet) were collected by a WDDS which was modified by our research group. The WDDS was manufactured from stainless steel and composed of two parts. The first part was the dry deposition section where dry deposition samples were collected in the periods when there was no rain and second part was the wet deposition section 

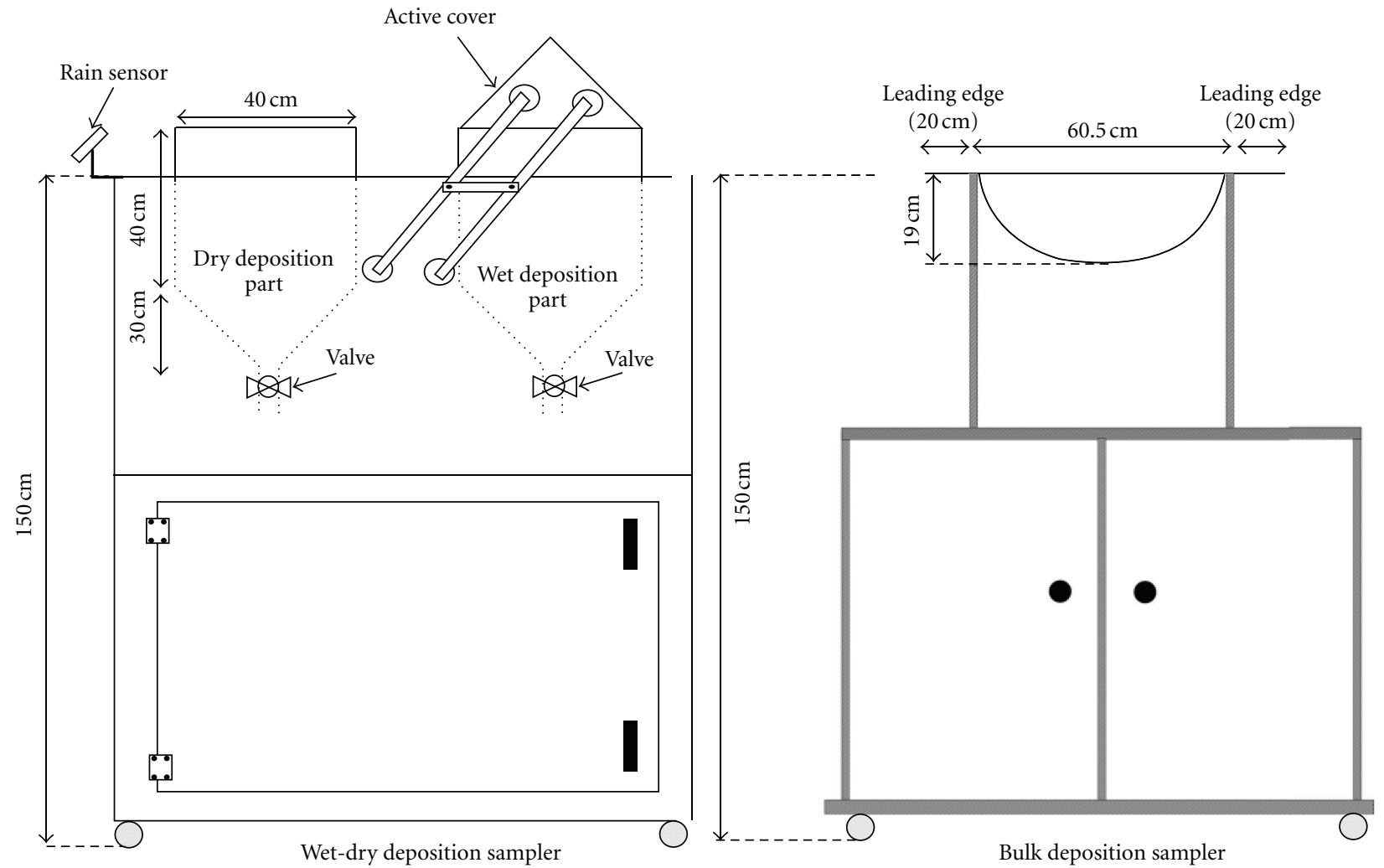

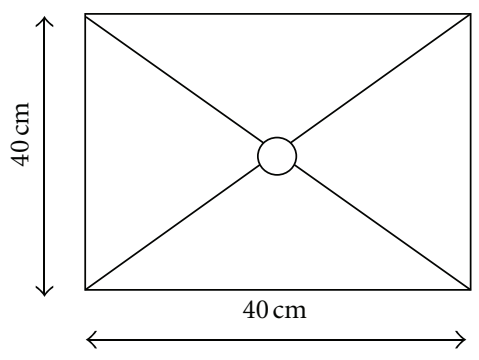

Top view

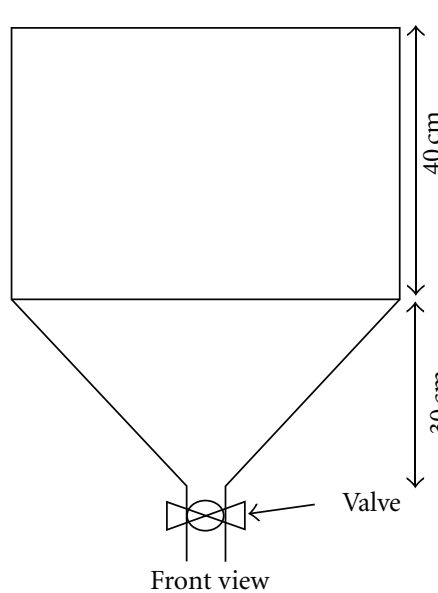

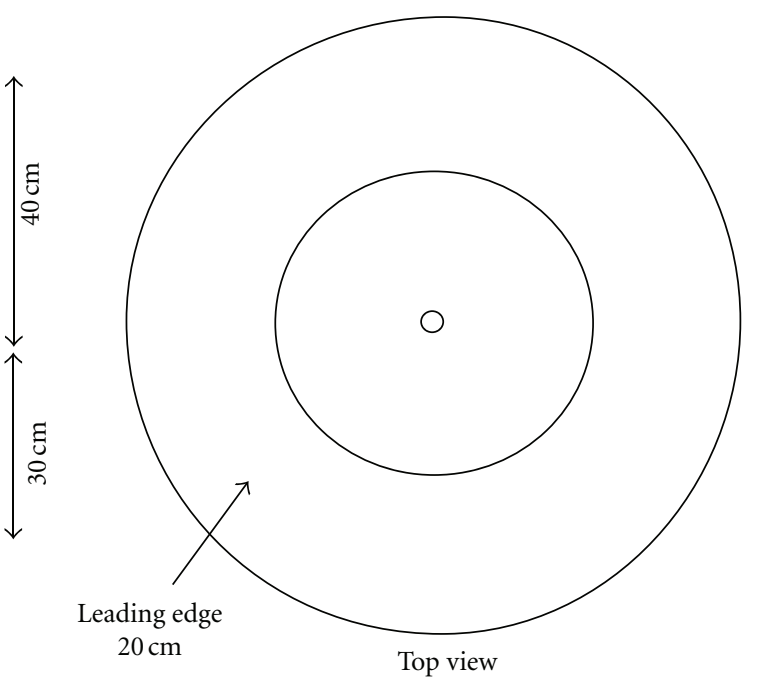

Bulk deposition sampler

FIGURE 1: Schematic display of wet dry deposition sampler (WDDS) and bulk deposition sampler (BDS).

where rain samples were collected in the rainy periods. There was an active cover on the device which operated after a signal was taken from the rain sensor. After rain stopped, the cover opened on top of the dry deposition part and closed on top of the wet deposition part. Details of the WDDS have been previously described elsewhere [17, 18]. Samples were taken for 15-day periods.

Bulk deposition samples were collected with bulk deposition samplers (BDSS) manufactured from stainless steel with a diameter of $60.5 \mathrm{~cm}$ and a depth of $19 \mathrm{~cm}$. There was a leading edge with a width of $20 \mathrm{~cm}$ in order to prevent negative effects of turbulence around the BDS [18]. The BDS and WDDS were run simultaneously. Schematic views of the WDDS and BDS are shown in Figure 1.

2.3. Analytical Procedure. Prior to extraction, the PUF, GFF and $\mathrm{XAD}-2$ resin samples were spiked with a surrogate standard consisting of PCB 14, РCB 65, and PCB $166(4 \mathrm{ng} / \mathrm{mL}$ each) to determine the analytical recoveries of the PCBs. The sampling, extraction, and analysis procedures followed 
in this study were explained elsewhere and were only summarized here $[17,18]$. Briefly, PUF cartridges were soxhlet extracted with a $1: 4(\mathrm{v}: \mathrm{v})$ mixture of DCM/PE (petroleum ether) for 24 hours [19]. HVAS filters were extracted with $25 \mathrm{~mL}$ DCM/PE (dichloromethane/petroleum ether, 1:4) mixture for 30 minutes in an ultrasonic bath (S80H, Elma GmbH Co., Germany). This step was repeated twice. Then, the bottle containing the sample was rinsed with the same $5 \mathrm{~mL}$ solvent mixture and added to other solvent mixture.

Before the collection of WDDS samples, the dry side was wiped clean with a paper napkin using ACE/HEX (acetone/ hexane, 1:1) mixture. At the end of the sampling period, the dry deposition side of the WDDS was again cleaned with a paper napkin and then ACE/HEX $(1: 1)$ was rinsed and finally was wiped with the paper napkin again. The paper napkins and ACE/HEX $(1: 1)$ mixture used in rinsing were kept in Teflon-coated jar. These dry deposition samples were extracted with $100 \mathrm{~mL}$ ACE/HEX (1:1) mixture in an ultrasonic bath for 30 minutes twice.

If there was water on the sampler due to rainfall, this was filtered through XAD-2 resin. The resin was then extracted with $100 \mathrm{~mL}$ ACE/HEX $(1: 1)$ mixture for 30 minutes with an ultrasonic bath. This process was repeated once more with another $100 \mathrm{~mL}$ ACE/HEX mixture. Bulk deposition samples were filtered through from sodium sulphate $\left(\mathrm{Na}_{2} \mathrm{SO}_{4}\right)$ after extraction in order to remove any residual water in the samples. The BDS surface was then rinsed with ACE/HEX mixture. This process was repeated a few times and the solvents were stored in a jar. Finally, the BDS surface was wiped with a paper napkin to remove contaminants from the surface and the used paper napkins were put into sample bottle so as to analyze them.

The volume of the extracted samples was reduced to $2 \mathrm{~mL}$ with the use of rotary evaporator and gentle stream of nitrogen $\left(\mathrm{N}_{2}\right)$, and these samples were passed through a cleanup column including $1 \mathrm{~cm}$ sodium sulphate $\left(\mathrm{Na}_{2} \mathrm{SO}_{4}\right)$, $2 \mathrm{~g}$ of aluminium oxide $(120 \mu \mathrm{L}$ pure water to $2 \mathrm{~g}$ of aluminium oxide), and $3 \mathrm{~g}$ of silica $(100 \mu \mathrm{L}$ pure water to $3 \mathrm{~g}$ of silica). The column was cleaned with $20 \mathrm{~mL}$ DCM and then with $25 \mathrm{~mL}$ PE. The volume of the PCB samples in $\mathrm{PE}$ was reduced to $5 \mathrm{~mL}$, and the solvent exchange was performed by adding $15 \mathrm{~mL}$ HEX. This was repeated twice. Finally, samples with reduced volume of $2 \mathrm{~mL}$ were rinsed with acid and taken to the vials. An internal standard solution consisting of PCB 30 and PCB 204 was added to concentrated samples for volume correction and internal standard was added just before the quantification of the PCB compounds.

Quantification of PCB congeners was conducted using an Agilent 7890A model gas chromatograph equipped with a $\mu$ ECD (Micro-Electron Capture Detector) (Hewlett-Packard, USA). GC-ECDs have been employed for PCB analysis in many studies because of their sensitivity [6, 20-22]. The oven temperature program used in the $\mathrm{PCB}$ analyses was $70^{\circ} \mathrm{C}$ ( $2 \mathrm{~min}$ ), increasing with $25^{\circ} \mathrm{C} / \mathrm{min}$ to $150^{\circ} \mathrm{C}$, then $3^{\circ} \mathrm{C} / \mathrm{min}$ to $200^{\circ} \mathrm{C}$, then $8^{\circ} \mathrm{C} / \mathrm{min}$ to $280^{\circ} \mathrm{C}$, followed by 8 minutes of holding under $280^{\circ} \mathrm{C}$, increasing with $10^{\circ} \mathrm{C} / \mathrm{min}$ to $300^{\circ} \mathrm{C}$ and holding for 2 minutes. The final program time was 41.87 minutes. The inlet temperature was kept at $250^{\circ} \mathrm{C}$ and the detector temperature was $320^{\circ} \mathrm{C}$. The carrying gas was helium $(\mathrm{He})(1.9 \mathrm{~mL} / \mathrm{min})$ and the make up gas was $\mathrm{N}_{2}(25 \mathrm{~mL} / \mathrm{min})$. HP5-MS $(30 \mathrm{~m} \times 0.32 \mathrm{~mm} \times 0.25 \mu \mathrm{m}$, Agilent, 19091 Je413) was used as a capillary column. For the calibration of the instrument, five levels of standard solutions ranging between 0.05 and $25 \mathrm{ng} / \mathrm{mL}$ were used for calibration. After each 25 samples injection, the medium standard was injected to check instrument stability. The instrument detection limit, IDL, was determined as $0.1 \mathrm{pg}$ for $1 \mu \mathrm{L}$ injection. The linear $r^{2}$ values determined with these standards varied between 0.99457 and 0.99996 for each PCB congener.

2.4. Quality Control (QC)/Quality Assurance (QA). A total of 83 PCB congeners were targeted in the collected samples: $\mathrm{PCB} \# 4 / 10, \# 9 / 7, \# 6, \# 8 / 5$, \#19, \#12/13, \#15/17, \#16/32, \#26, \#31, \#28, \#21, \#53, \#22, \#45, \#52, \#47, \#49/48, \#44, \#37/42, \#71/41/64, \#100, \#74, \#70/61, \#66/95, \#91, \#56/60, \#92, \#84, \#89/101, \#99, \#119, \#83, \#81/87, \#86, \#85, \#77/110, \#135/144, \#114/149, \#118, \#123, \#131, \#153, \#132/105, \#163/138, \#126, \#128, \#167, \#174, \#202/171/156, \#172, \#180, \#200, \#170/190, \#169, \#199, \#207, \#194, \#205, and \#206.

In order to determine the probable contamination generated during sampling, extraction, and analysis, $10 \%$ of the total samples were taken as blank samples. Same transportation, extraction, and analysis procedure applied to the real samples were employed to the blanks.

The limit of detection (LOD) values were calculated by adding three times standard deviations of the blank samples to the average PCB concentrations in the blank samples [2326]. LOD values were determined for each PCB congener and data smaller than the LOD values were neglected.

The ratio of the average PCB value obtained in the blank samples to the PCB values determined in the samples were found as $5.7 \pm 3.5 \%$ for GFF, $1.7 \pm 1.0 \%$ for PUF, $3.0 \pm 2.8 \%$ for WDDS, and $3.3 \pm 3.5 \%$ for the BDS. The average recovery efficiencies for the PCB 14, PCB 65, and PCB 166 were shown in Table 2. All results in this study have been reported after surrogate and internal correction.

\section{Results and Discussions}

3.1. Ambient Air Concentrations. During the sampling period, 34 atmospheric air samples were collected by means of the HVAS. Two samples were collected in the first half of the month and the other two were taken in the second half when there was no rain. The average gas and particulate phase $\mathrm{PCB}$ concentrations (mean $\pm \mathrm{SD}$ ) were $320 \pm 110 \mathrm{pg} / \mathrm{m}^{3}$ and $40 \pm 30 \mathrm{pg} / \mathrm{m}^{3}$, respectively. Total PCB concentration was determined to be $360 \pm 100 \mathrm{pg} / \mathrm{m}^{3}$ at the YS sampling site. These levels of concentrations were among the high levels determined in urban sites (Table 3) [3, 4, 29, 31]. The high PCB levels suggested that the occurrence of PCBs was due to local sources and long-range transport. The area of Northwestern Turkey is known as an area with mid to high concentrations of PCBs and many studies have been conducted last years to describe the situation [16-18, 22, 33]. The most abundant individual congeners, in this study, were PCB-85, PCB-52, and PCB-28 with average concentrations 
TABLE 2: Recovery efficiencies for the HVAS and BDS samplers.

\begin{tabular}{lccccc}
\hline \multirow{2}{*}{ Congeners } & \multicolumn{2}{c}{ HVAS } & \multicolumn{2}{c}{ WDDS } & Resin \\
& Filter & PUF & Filter & $47.16 \pm 17.70$ & $54.20 \pm 11.46$ \\
PCB\#14 & $56.16 \pm 14.79$ & $70.22 \pm 23.52$ & $50.45 \pm 25.83$ & $58.57 \pm 18.78$ & $77.25 \pm 19.85$ \\
PCB\#65 & $62.50 \pm 17.19$ & $64.22 \pm 18.33$ & $67.47 \pm 19.62$ & $72.30 \pm 22.38$ & $92.00 \pm 17.74$ \\
PCB\#166 & $75.60 \pm 23.20$ & $77.44 \pm 22.67$ & $88.26 \pm 26.55$ & & 75 \\
\hline
\end{tabular}

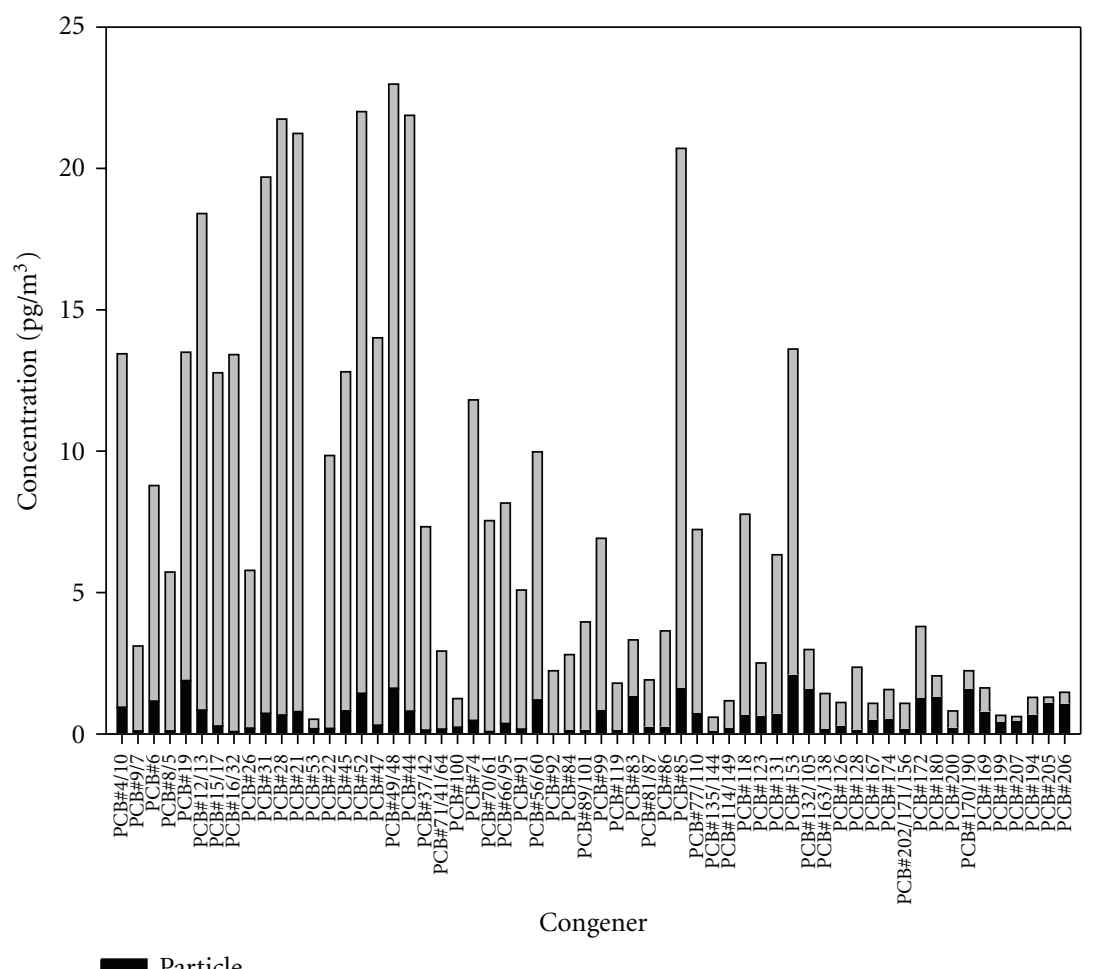

$\square$ Particle
Gas

FIGURE 2: Distribution of the average gas/particulate concentrations of the PCB congeners.

of $23.6,21.3,20.8 \mathrm{pg} / \mathrm{m}^{3}$, respectively. Regarding the other congeners of the typical seven PCB-mix, they occurred in various concentrations with the following order: PCB-153< PCB-118< PCB- $101<$ PCB- $180<$ PCB-138 (Figure 2).

The distribution between gas and particulate phase $\mathrm{PCB}$ congeners is shown in Figure 2. It can be seen that 90\% of the total PCB burden was in the gas phase and lower molecular weight PCBs were more dominant in the collected samples because they partition mainly in the gas phase. The heavier PCBs (octa- and nona-CBs) were dominant in particulate phase because they tend to sorb onto the particulates in percents that are as high as $80 \%$. Measured gas and particulate phase concentrations were higher than the rural site values but lower than some urban site values $[3,12,24,30,31]$. Various researchers were studied on PCBs in different regions and measured gas-particle phase levels are shown in Table 3.

PCBs usually exhibit seasonality, with summer values being higher than the winter ones due to the evaporation that takes place from different surfaces facilitated by the higher summer temperatures $[12,22,25]$.
Total organic compound (TOC) levels were determined in the collected samples, because the TOC level might affect the sorption quantities of PCBs. In YS, the TOC content was measured for summer, fall, winter, and spring seasons as $12.3 \pm 1.1,3.02 \pm 0.3,3.91 \pm 2.7$, and $2.52 \pm 0.19 \%$, respectively. The values of TOCs were more than $10 \%$ in summer for YS sampling site.

3.2. Dry and Bulk Deposition Fluxes. Samples $(n=23)$ were taken over biweekly (every 15 days) with BDS and WDDS, simultaneously. During the sampling, BDS was exposed to the atmosphere all the time while WDDS was sampling only during dry weather conditions. The average flux values of WDDS and BDS were $5500 \pm 2400 \mathrm{pg} /\left(\mathrm{m}^{2}\right.$ day $)$ and $7200 \pm 3500 \mathrm{pg} /\left(\mathrm{m}^{2}\right.$ day $)$, respectively. Dry deposition and bulk deposition flux values obtained in other studies carried out in different areas and taken from the literature are summarized in Table 4. Although it was mentioned earlier that the air concentrations of PCBs were quite high in YS site, the deposition values were lower than in past studies $[3,14,33-36]$. Comparing the present values with relevant 
TABLE 3: Atmospheric concentrations of PCBs at various locations.

\begin{tabular}{|c|c|c|c|c|c|}
\hline Location & & Period & $n^{*}$ & Concentration $\left(\mathrm{pg} / \mathrm{m}^{3}\right)$ & Reference \\
\hline Paris, France & (Urban) & 1989-1990 & 12 & $2000-6000$ & {$[3]$} \\
\hline Cumbria, UK & (Coastal) & 1996-1997 & 52 & 318 & {$[27]$} \\
\hline \multirow{2}{*}{ Athens, Greece } & (Urban) & \multirow{2}{*}{2000 July } & \multirow{2}{*}{38} & 344.9 & \multirow{2}{*}[4]{} \\
\hline & (Coastal) & & & 181.1 & \\
\hline \multirow{2}{*}{ Thessaloniki, Greece } & (Rural) & March 1999 & \multirow{2}{*}{6} & $0.5-29.2$ & \multirow{2}{*}{ [28] } \\
\hline & (Semirural) & October 1999 & & $0.5-15.6$ & \\
\hline \multirow{2}{*}{ Zagreb, Croatia } & \multirow{2}{*}{ (Urban) } & June 1999 & \multirow{2}{*}{20} & 8.2-968.6 (gas) & \multirow{2}{*}[29]{} \\
\hline & & February 2000 & & 11.2-859.1 (particle) & \\
\hline \multirow{2}{*}{ Madrid, Spain } & \multirow{2}{*}{ (Urban) } & February 1998 & \multirow{2}{*}{31} & \multirow{2}{*}{$120-4300$} & \multirow{2}{*}[30]{} \\
\hline & & June 1998 & & & \\
\hline Stockholm, Sweden & (Urban) & 1991-1996 & 63 & $3300-6800$ & {$[31]$} \\
\hline \multirow{2}{*}{ Ansung, Korea } & \multirow{2}{*}{ (Rural) } & July 1999 & \multirow{2}{*}{38} & \multirow{2}{*}{$6.13-71.9$} & \multirow{2}{*}[23]{} \\
\hline & & June 2000 & & & \\
\hline \multirow{2}{*}{ Venice Lagoon } & \multirow{2}{*}{ (Urban) } & August 2002 & \multirow{2}{*}{54} & 421 (gas) & \multirow{2}{*}[24]{} \\
\hline & & September 2002 & & 11 (particle) & \\
\hline \multirow{2}{*}{ Elm Road, England } & \multirow{2}{*}{ (Semirural) } & April 1999 & \multirow{2}{*}{12} & \multirow{2}{*}{$252($ gas + particle $)$} & \multirow{2}{*}[32]{} \\
\hline & & July 2000 & & & \\
\hline \multirow{2}{*}{ Chicago, USA } & \multirow{2}{*}{ (Urban) } & June 1995 & 50 & 1820 (gas) & [1? \\
\hline & & October 1995 & & 90 (particle) & {$[12]$} \\
\hline Eordea, Greece & (Industrial) & January 2001 & 8 & 0.04-103 (particle) & {$[25]$} \\
\hline & & June 2001 & & & {$[25]$} \\
\hline Yokohama, Japan & (Urban) & March 2002 & 12 & $62-250$ (gas + particle $)$ & {$[26]$} \\
\hline & & February 2003 & & & {$[20]$} \\
\hline Uludag University & (Semirural) & July 2004 & 24 & $328 \pm 284$ (gas) & {$[32$} \\
\hline Campus, Turkey & & May 2005 & & $86 \pm 128$ (particle) & {$[30]$} \\
\hline Yavuzselim, Turkey & (Residential) & June 2008 & 83 & $320 \pm 110$ (gas) & This study \\
\hline & & June 2009 & & $40 \pm 30($ particle $)$ & \\
\hline
\end{tabular}

study in the same city, the results are at the same order of magnitude [16], The parameters that generally affect the deposition fluxes are the sampler type, the atmospheric PCB concentrations, the sampling site characteristics, and the sampling period.

Samples of BDS and WDDS taken only during dry periods were used to compare the dry deposition fluxes. The purpose of this comparison was to determine the possible effects of sampler types on the measured fluxes. The average total deposition flux measured with the BDS in dry periods was $5500 \pm 2400 \mathrm{pg} /\left(\mathrm{m}^{2}\right.$ day $)$ while in the same period, the average dry deposition flux value measured with the WDDS was $6400 \pm 3200 \mathrm{pg} /\left(\mathrm{m}^{2}\right.$ day $)$. Temporal variations of measured flux values are illustrated in Figure 3. Results indicate that the shape of samplers considerably affected the flux obtained. Both samplers were made of stainless steel; thus, both samplers collected only particle phase PCBs. The shapes of collection surfaces caused the deposited particles to re-suspend into the atmosphere at different amounts. Particles deposited onto the BDS having shallow depth could be re-suspended more easily with the help of wind. This caused a decrease in the flux amount. On the other hand, WDDS had a deeper collection structure with a depth of about $70 \mathrm{~cm}$ thus losses due to resuspension were less significant. The wind speed proved to be another important factor affecting the flux ratio. For example, the $F_{\mathrm{WDDS}} / F_{\mathrm{BDS}}$ values determined for three different wind speeds of $<1 \mathrm{~m} / \mathrm{s}$, $1-1.5 \mathrm{~m} / \mathrm{s}$ and $>1.5 \mathrm{~m} / \mathrm{s}$ yielded ratios of $0.73,1.52$, and 1.59 , respectively.

When the PCB homolog group distributions of flux values which were obtained with the WDDS and BDS in the same period were analyzed, it was determined that 3 -CBs and 4 -CBs were dominant in this period. Homolog profiles of PCBs from both samplers for the same period are shown in Figure 4. The two profiles exhibited significant positive correlation (Figure 5(a), $r^{2}=0.61, P<0.05$ ). The profiles under both sampling modes were different comparing to the ambient profile (Figure 2) for which the light PCBs were prevalent. Instead, in the deposition profiles the tetra-CBs were most abundant accounting more than $35 \%$ of the total PCBs. The reason for this fact is that the gas phase which is enriched in lighter PCBs is not deposited in the same extent as the particulate phase.

Bulk deposition samples were collected with the BDS in rainy periods, as well. Average bulk deposition flux values from rainy period samples were $8700 \pm 3100 \mathrm{pg} /\left(\mathrm{m}^{2}\right.$ day $)$ 


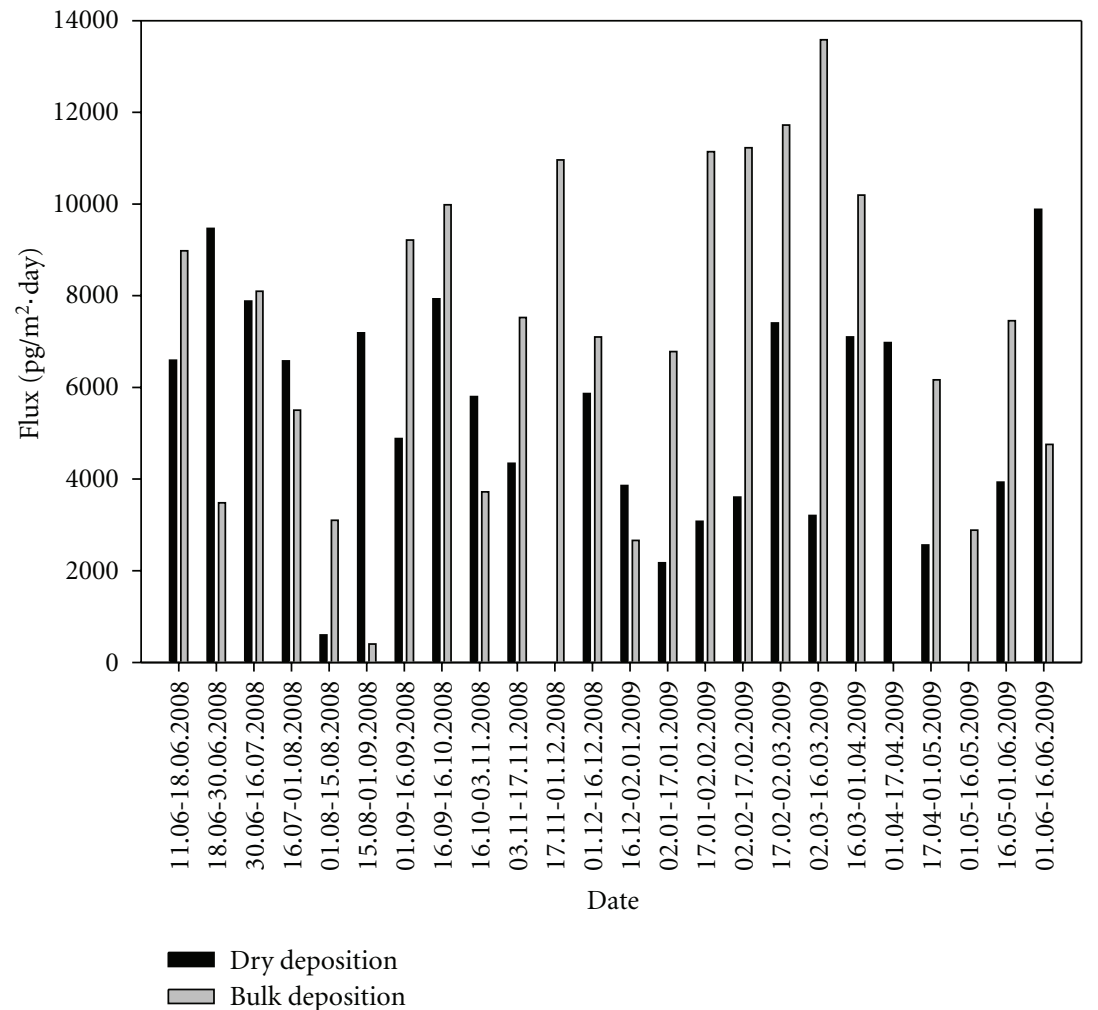

FIgURE 3: Temporal variation of dry and bulk deposition flux values.

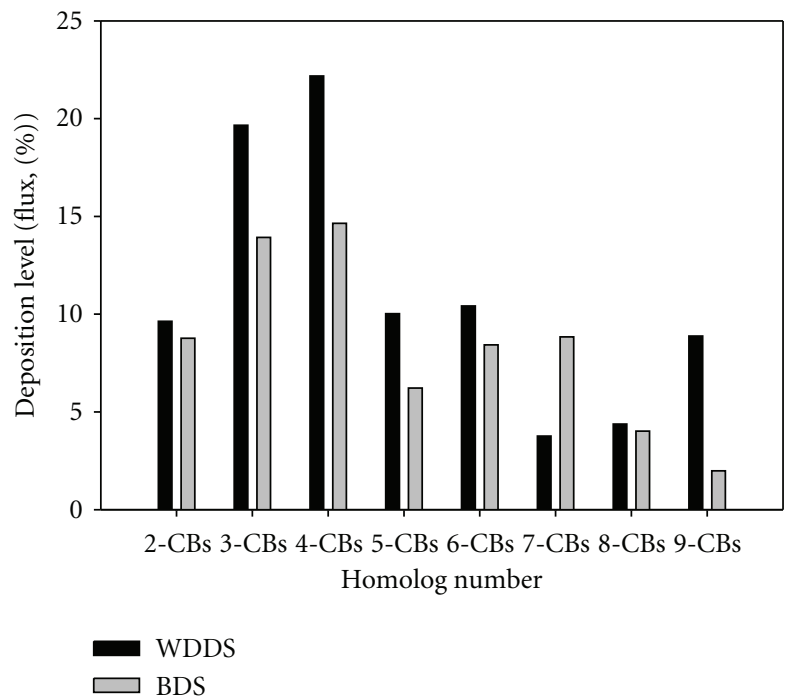

FIGURE 4: PCB homolog distribution of dry deposition flux samples.

and were higher than the flux values obtained with the BDS in dry periods. Transport of the particulates with the rain and absorption of the gas phase PCBs into the rain drops according to Henry's law were reported in the literature for SVOCs [39-42]. These combined processes likely caused higher fluxes in rainy periods. Another reason for higher fluxes was deposited rain water on the BDS. The water on the BDS sampler captures particulates and particulates containing PCBs do not bounce off when they hit the water surface [34]. Moreover, the aqueous phase moves towards equilibrium with gas phase PCBs, transporting them to the deposition collector.

A relationship between rain volume and rainy period flux values of BDS was examined, but no statistically significant relationship was found (Figure 5(b), $P>0.05$ ). However, there was a positive correlation and it indicated that 
TABLE 4: Dry and bulk deposition flux values obtained at different sampling site.

\begin{tabular}{|c|c|c|c|c|c|}
\hline Sampling site & Period & $n^{*}$ & $\begin{array}{c}\text { Flux } \\
\left(\mathrm{ng} /\left(\mathrm{m}^{2} \text { day }\right)\right)\end{array}$ & Sampler type & Reference \\
\hline \multicolumn{6}{|l|}{ Dry deposition } \\
\hline Paris, France (Urban) & 1989 & 12 & 79 & Stainless-steel funnel & {$[3]$} \\
\hline $\begin{array}{l}\text { Sleeping Bear Dunes, MI, USA } \\
\text { (Rural) }\end{array}$ & 1993-1995 & 44 & 60 & Mylar strips, Apiezon L. grease & {$[14]$} \\
\hline Chicago, IL, USA (Urban) & June-October 1995 & - & 240 & WSS & {$[34]$} \\
\hline Bursa, Turkey (Suburban) & July 2004-May 2005 & 41 & $40.6 \pm 40.6$ & WSS & {$[33]$} \\
\hline Bursa, Turkey (Urban, Traffic site) & July 2004-May 2005 & 41 & $86.0 \pm 97.4$ & WSS & {$[35]$} \\
\hline $\begin{array}{l}\text { Yavuzselim, Bursa, Turkey } \\
\text { (Residential) }\end{array}$ & $\begin{array}{l}\text { June 2008-June } \\
2009\end{array}$ & 83 & $5.50 \pm 2.50$ & WDDS & This study \\
\hline \multicolumn{6}{|l|}{ Bulk deposition } \\
\hline P. Marghera. Italy (Industrial) & 1998-1999 & - & 7.3 & Pyrex funnel & {$[37]$} \\
\hline Valle Figeri Italy (Far-clean) & 1998-1999 & - & 1.5 & Pyrex funnel & {$[37]$} \\
\hline Tsukuba. Japan (Semirural) & 1997-1998 & 12 & 0.3 & Stainless-steel vessel & {$[38]$} \\
\hline Galveston Bay. USA (Coastal) & Feb. 1995-Aug. 1996 & 22 & 17.5 & $\begin{array}{l}\text { Wet deposition and } \\
\text { calculation }\end{array}$ & {$[36]$} \\
\hline $\begin{array}{l}\text { BOID Bursa. TR } \\
\text { (Urban/Industrial) }\end{array}$ & July 2004-May 2005 & 41 & $15.4 \pm 14.3$ & Stainless-steel vessel & {$[16]$} \\
\hline Gülbahçe, TR (Urban) & July 2004-May 2005 & 41 & $36.1 \pm 21.3$ & Stainless-steel vessel & {$[35]$} \\
\hline Yavuzselim, TR (Residential) & $\begin{array}{l}\text { June 2008-June } \\
2009\end{array}$ & 83 & $7.20 \pm 3.50$ & Stainless-steel vessel & This study \\
\hline
\end{tabular}

${ }^{*} F=V_{d} \times C\left(V_{d}=0.2 \mathrm{~cm} / \mathrm{s}\right)$.

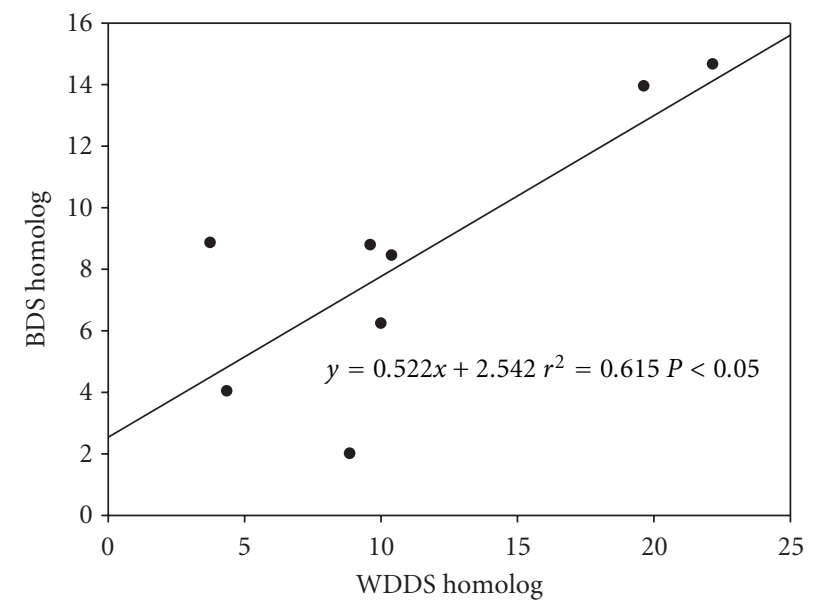

(a)

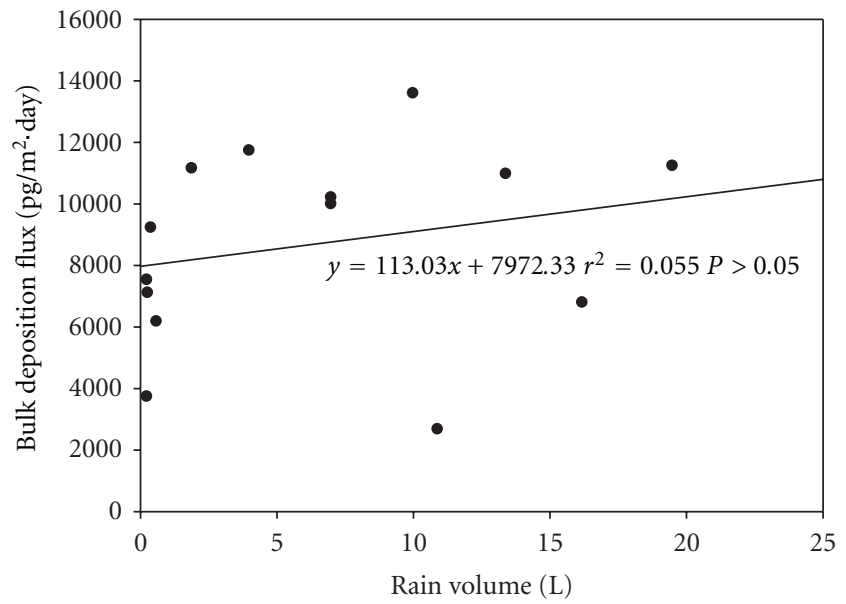

(b)

FIGURE 5: (a) Relationship between WDDS homolog distributions and BDS homolog distributions, and (b) relationship between rainy period bulk deposition fluxes and rain volumes.

deposition flux increased depending on an increase in the rain volume.

The average dry deposition flux value was $4700 \pm$ $1900 \mathrm{pg} /\left(\mathrm{m}^{2} \mathrm{day}\right)$ for the WDDS in rainy periods. This was smaller than the value obtained with the BDS. Washout of PCBs from the atmosphere by precipitation caused a decrease of dry deposition flux values in this period.

It has been examined whether this situation resembles within the flux values. In this scope, higher dry deposition fluxes were obtained with the WDDS in hotter seasons with no rain, while higher deposition fluxes were obtained for bulk deposition fluxes in rainy season.

3.3. Dry and Bulk Deposition Velocities. The PCB flux values $\left(F_{\mathrm{p}}\right)$ were divided by the particle phase PCB concentration $\left(C_{\mathrm{p}}\right)$ values while calculating the dry deposition velocity $\left(V_{d}\right)$ values for the WDDS. This calculation was a little different for BDS. If only dry season values were calculated, this approach would be applicable for the BDS, either. On the other hand, the dry and wet depositions were observed at the 
same time in some samples. In these cases, flux value was divided by total concentration (gas + particle) and this new velocity can be named as bulk deposition velocity.

Dry deposition velocity values which were obtained for WDDS and BDS collected in the same periods were $0.48 \pm 0.35 \mathrm{~cm} / \mathrm{s}$ and $0.13 \pm 0.15 \mathrm{~cm} / \mathrm{s}$, respectively. This difference was mainly caused by the wind effects as a result of the samplers shape. The deposition velocity obtained in rainy periods with $\mathrm{BDS}$ was $0.11 \pm 0.04 \mathrm{~cm} / \mathrm{s}$. This was a little smaller than the one calculated for dry periods. This was probably because not only particulate but also gas phase deposition occurred simultaneously and the gas phase deposition velocity was lower than particulate phase [43].

It was determined that while 5-CBs, 6-CBs, and 8-CBs had higher deposition velocity in the rainy period samples of the BDS, while 7-CBs and 8-CBs had greater deposition velocities in dry period samples in which only dry deposition occurred.

It should also be noted that sampling site characteristics, atmospheric particulate matter concentrations and meteorological parameters play a crucial role on the variations of the deposition velocities.

\section{Conclusions}

Deposition fluxes and concentrations of the PCBs were measured between June 2008 and June 2009. The measured gas and particulate phase concentrations were higher than the values reported for the rural areas but lower than the values given for the urban areas.

Flux values were measured with two different samplers (WDDS and BDS). Average fluxes of WDDS in dry period were higher than the one measured with the BDS. This difference was mainly due to the shape of the sampler because both samplers were run side-by-side simultaneously. On the other hand, fluxes measured with the BDS were higher during the rainy periods. This was mainly due to scavenging of PCBs with the precipitation, capturing of the particulate phase PCBs, and absorption of gas phase PCBs into the water on the BDS. However, there was no significant relationship between rain volume and flux measured with the BDS in rainy periods.

Dry deposition velocity values calculated for the WDDS were higher when compared to dry deposition velocity values which were obtained with the BDS when there was no rainfall. Deposition velocity values obtained from the BDS differentiated depending on the dry and rainy periods. Rainy period values were lower due to the effect of gas phase. When homolog distributions of PCBs in bulk deposition velocity were examined, it was determined that 5-CBs, 6-CBs, and 8CBs had higher deposition velocity in rainy period samples while 7-CBs and 8-CBs had more dominant characteristics in dry period samples.

Different parameters such as sampler type, atmospheric concentrations, meteorological parameters, sampling site characteristics, and sampling periods had effects on deposition mechanisms of the PCBs.

\section{Acknowledgments}

This study was financially supported by The Scientific and Technological Research Council of Turkey (TUBITAK, Project number 107Y165). The authors would like to thank Dr. S. Siddik Cindoruk (Engineering Department, Uludag University Environmental) for his help in GC-ECD analyses. The authors also thank Manolya Günindi for her contributions in the tiresome sampling and laboratory studies.

\section{References}

[1] K. Breivik, A. Sweetman, J. M. Pacyna, and K. C. Jones, "Towards a global historical emission inventory for selected PCB congeners-a mass balance approach. 3. An update," Science of the Total Environment, vol. 377, no. 2-3, pp. 296$307,2007$.

[2] R. A. Rudel, L. M. Seryak, and J. G. Brody, "PCB-containing wood floor finish is a likely source of elevated PCBs in residents' blood, household air and dust: a case study of exposure," Environmental Health, vol. 7, pp. 2-8, 2008.

[3] L. K. Granier and M. Chevreuil, "Behaviour and spatial and temporal variations of polychlorinated biphenyls and lindane in the urban atmosphere of the Paris area, France," Atmospheric Environment, vol. 31, no. 22, pp. 3787-3802, 1997.

[4] M. Mandalakis, M. Tsapakis, A. Tsoga, and E. G. Stephanou, "Gas-particle concentrations and distribution of aliphatic hydrocarbons, PAHs, PCBs and PCDD/Fs in the atmosphere of Athens (Greece)," Atmospheric Environment, vol. 36, no. 25, pp. 4023-4035, 2002.

[5] P. A. Brunciak, J. Dachs, C. L. Gigliotti, E. D. Nelson, and S. J. Eisenreich, "Atmospheric polychlorinated biphenyl concentrations and apparent degradation in coastal New Jersey," Atmospheric Environment, vol. 35, no. 19, pp. 33253339, 2001.

[6] T. Harner, D. Mackay, and K. C. Jones, "Model of the longterm exchange of PCBs between soil and the atmosphere in the Southern U.K," Environmental Science and Technology, vol. 29, no. 5, pp. 1200-1209, 1995.

[7] L. A. Totten, P. A. Brunciak, C. L. Gigliotti et al., "Dynamic air-water exchange of polychlorinated biphenyls in the New York-New Jersey harbor estuary," Environmental Science and Technology, vol. 35, no. 19, pp. 3834-3840, 2001.

[8] J. D. Jeremiason, K. C. Hornbuckle, and S. J. Eisenreich, "PCBs in Lake Superior, 1978-1992: decreases in water concentrations reflect loss by volatilization," Environmental Science and Technology, vol. 28, no. 5, pp. 903-914, 1994.

[9] S. Yan, L. A. Rodenburg, J. Dachs, and S. J. Eisenreich, "Seasonal air-water exchange fluxes of polychlorinated biphenyls in the Hudson River Estuary," Environmental Pollution, vol. 152, no. 2, pp. 443-451, 2008.

[10] B. J. Finlayson-Pitts and J. N. Pitts, Atmospheric Chemistry: Fundamentals and Experimental Techniques, John Wiley \& Sons, New York, NY, USA, 1986.

[11] R. M. Hoff, W. M. J. Strachan, C. W. Sweet et al., "Atmospheric deposition of toxic chemicals to the Great Lakes: a review of data through 1994," Atmospheric Environment, vol. 30, no. 20, pp. 3505-3527, 1996.

[12] Y. Tasdemir, N. Vardar, M. Odabasi, and T. M. Holsen, "Concentrations and gas/particle partitioning of PCBs in Chicago," Environmental Pollution, vol. 131, no. 1, pp. 35-44, 2004. 
[13] U. Dämmgen, J. W. Erisman, J. N. Cape, L. Grünhage, and D. Fowler, "Practical considerations for addressing uncertainties in monitoring bulk deposition," Environmental Pollution, vol. 134, no. 3, pp. 535-548, 2005.

[14] T. P. Franz, S. J. Eisenreich, and T. M. Holsen, "Dry deposition of particulate polychlorinated biphenyls and polycyclic aromatic hydrocarbons to Lake Michigan," Environmental Science and Technology, vol. 32, no. 23, pp. 3681-3688, 1998.

[15] J. C. Chow, J. G. Watson, L. A. Chen et al., "Exposure to PM2.5 and PAHs from the Tong Liang, China epidemiological study," Journal of Environmental Science and Health Part A, vol. 41, no. 4, pp. 517-542, 2006.

[16] S. S. Cindoruk, F. Esen, N. Vardar, and Y. Tasdemir, "Measurement of atmospheric deposition of polychlorinated biphenyls and their dry deposition velocities in an urban/industrial site in Turkey," Journal of Environmental Science and Health Part A Toxic/Hazardous Substances and Environmental Engineering, vol. 43, no. 11, pp. 1252-1260, 2008.

[17] M. Günindi and Y. Tasdemir, "Wet and dry deposition fluxes of polychlorinated biphenyls (PCBs) in an urban area of Turkey," Water, Air and Soil Pollution, vol. 215, pp. 427-439, 2010.

[18] A. Birgul and Y. Tasdemir, "Seasonal atmospheric deposition variations of polychlorinated biphenyls (PCBs) and comparison of some deposition sampling techniques," Environmental Science and Pollution Research, vol. 18, pp. 396-406, 2011.

[19] F. Esen, S. S. Cindoruk, and Y. Tasdemir, "Ambient concentrations and gas/particle partitioning of polycyclic aromatic hydrocarbons in an urban site in Turkey," Environmental Forensics, vol. 7, no. 4, pp. 1-10, 2006.

[20] L. Shen, F. Wania, Y. D. Lei, C. Teixeira, D. C. G. Muir, and H. Xiao, "Polychlorinated biphenyls and polybrominated diphenyl ethers in the North American atmosphere," Environmental Pollution, vol. 144, no. 2, pp. 434-444, 2006.

[21] M. D. Fang, F. C. Ko, J. E. Baker, and C. L. Lee, "Seasonality of diffusive exchange of polychlorinated biphenyls and hexachlorobenzene across the air-sea interface of Kaohsiung Harbor, Taiwan," Science of the Total Environment, vol. 407, no. 1, pp. 548-565, 2008.

[22] S. S. Cindoruk and Y. Tasdemir, "Dynamics of atmospheric polychlorinated biphenyls (PCBs): concentrations, patterns, partitioning, and dry deposition level estimations in a residential site of Turkey," Environmental Monitoring and Assessment, vol. 162, no. 1-4, pp. 67-80, 2010.

[23] H. G. Yeo, M. Choi, M. Y. Chun, and Y. Sunwoo, "Gas/particle concentrations and partitioning of PCBs in the atmosphere of Korea," Atmospheric Environment, vol. 37, no. 25, pp. 3561$3570,2003$.

[24] A. Gambaro, L. Manodori, I. Moret, G. Capodaglio, and P. Cescon, "Determination of polychlorobiphenyls and polycyclic aromatic hydrocarbons in the atmospheric aerosol of the Venice Lagoon," Analytical and Bioanalytical Chemistry, vol. 378, no. 7, pp. 1806-1814, 2004.

[25] M. Biterna and D. Voutsa, "Polychlorinated biphenyls in ambient air of NW Greece and in particulate emissions," Environment International, vol. 31, no. 5, pp. 671-677, 2005.

[26] K. S. Kim and S. Masunaga, "Behavior and source characteristic of PCBS in urban ambient air of Yokohama, Japan," Environmental Pollution, vol. 138, no. 2, pp. 290-298, 2005.

[27] B. Gevao, J. Hamilton-Taylor, and K. C. Jones, "Polychlorinated biphenyl and polycyclic aromatic hydrocarbon deposition to and exchange at the air-water interface of Esthwaite Water, a small lake in Cumbria, UK," Environmental Pollution, vol. 102, no. 1, pp. 63-75, 1998.

[28] T. Kouimtzis, C. Samara, D. Voutsa, C. Balafoutis, and L. Müller, "PCDD/Fs and PCBs in airborne particulate matter of the greater Thessaloniki area, N. Greece," Chemosphere, vol. 47, no. 2, pp. 193-205, 2002.

[29] H. Romanic and B. Krauthacker, "Comparison of ambient air levels of PCBs and organochlorine pesticides at two sites in Zagreb, Croatia," Bulletin of Environmental Contamination and Toxicology, vol. 71, no. 5, pp. 1034-1041, 2003.

[30] S. G. Alonso and R. M. P. Pastor, "Occurence of PCBs in ambient air and surface soil in an urban site in Madrid," Water, Air, and Soil Pollution, vol. 146, no. 1-4, pp. 283-295, 2003.

[31] R. Ishaq, C. Näf, Y. Zebühr, D. Broman, and U. Järnberg, "PCBs, PCNs, PCDD/Fs, PAHs and Cl-PAHs in air and water particulate samples-patterns and variations," Chemosphere, vol. 50, no. 9, pp. 1131-1150, 2003.

[32] S. Harrad and H. Mao, "Atmospheric PCBs and organochlorine pesticides in Birmingham, UK: concentrations, sources, temporal and seasonal trends," Atmospheric Environment, vol. 38, no. 10, pp. 1437-1445, 2004.

[33] S. S. Cindoruk and Y. Tasdemir, "Deposition of atmospheric particulate PCBs in suburban site of Turkey," Atmospheric Research, vol. 85, no. 3-4, pp. 300-309, 2007.

[34] Y. Tasdemir and T. M. Holsen, "Measurement of particle phase dry deposition fluxes of polychlorinated biphenyls (PCBs) with a water surface sampler," Atmospheric Environment, vol. 39, no. 10, pp. 1845-1854, 2005.

[35] S. S. Cindoruk, Determination of the concentrations, dry deposition and air-water interface fluxes of PCBs, Ph.D. thesis, Science Institute, Uludag University, Bursa, Turkey, 2007.

[36] J. S. Park, T. L. Wade, and S. Sweet, "Atmospheric distribution of polycyclic aromatic hydrocarbons and deposition to Galveston Bay, Texas, USA," Atmospheric Environment, vol. 35, no. 19, pp. 3241-3249, 2001.

[37] P. Rossini, S. Guerzoni, E. Molinaroli, G. Rampazzo, A. de Lazzari, and A. Zancanaro, "Atmospheric bulk deposition to the lagoon of Venice. Part I. Fluxes of metals, nutrients and organic contaminants," Environment International, vol. 31, no. 7, pp. 959-974, 2005.

[38] I. Ogura, S. Masunaga, and J. Nakanishi, "Atmospheric deposition of polychlorinated dibenzo-p-dioxins, polychlorinated dibenzofurans, and dioxin-like polychlorinated biphenyls in the Kanto region, Japan," Chemosphere, vol. 44, no. 6, pp. 1473-1487, 2001.

[39] J. C. Duinker and F. Bouchertall, "On the distribution of atmospheric polychlorinated biphenyl congeners between vapor phase, aerosols, and rain," Environmental Science and Technology, vol. 23, no. 1, pp. 57-62, 1989.

[40] D. L. Poster and J. E. Baker, "Influence of submicron particles on hydrophobic organic contaminants in precipitation. 1. Concentrations and distributions of polycyclic aromatic hydrocarbons and polychlorinated biphenyls in rainwater," Environmental Science and Technology, vol. 30, no. 1, pp. 341348, 1996.

[41] D. L. Poster and J. E. Baker, "Influence of submicron particles on hydrophobic organic contaminants in precipitation. 2. Scavenging of polycyclic aromatic hydrocarbons by rain," Environmental Science and Technology, vol. 30, no. 1, pp. 349$354,1996$.

[42] J. H. Offenberg and J. E. Baker, "Precipitation scavenging of polychlorinated biphenyls and polycyclic aromatic hydrocarbons along an urban to over-water transect," Environmental Science and Technology, vol. 36, no. 17, pp. 3763-3771, 2002.

[43] D. M. Wethington and K. C. Hornbuckle, "Milwaukee, WI, as a source of atmospheric PCBs to Lake Michigan," Environmental Science and Technology, vol. 39, no. 1, pp. 5763, 2005. 

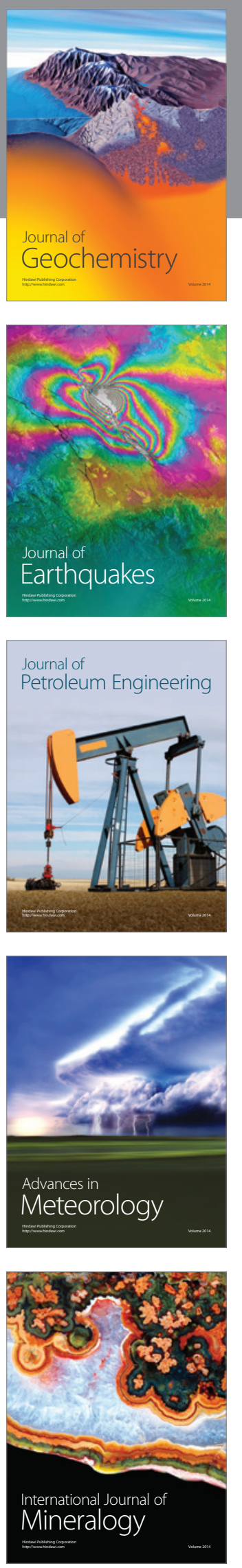
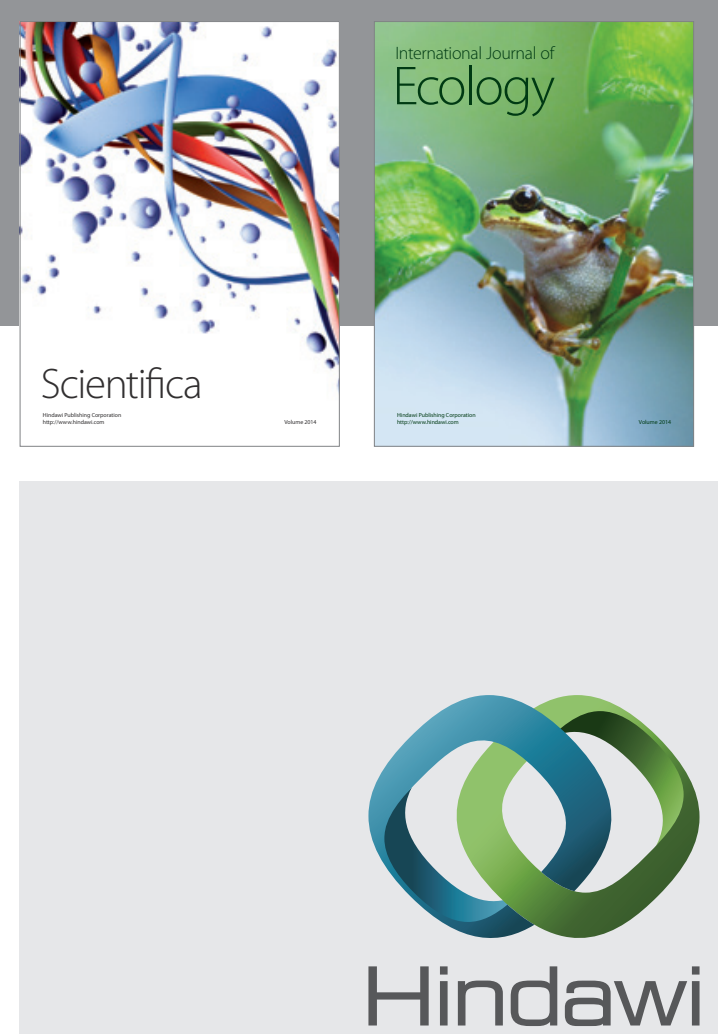

Submit your manuscripts at http://www.hindawi.com
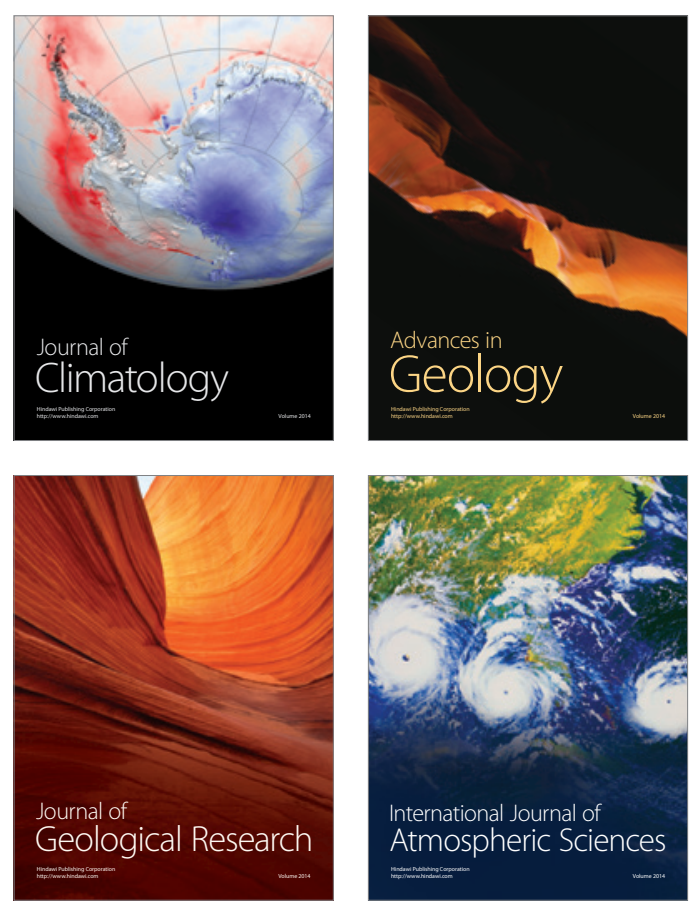
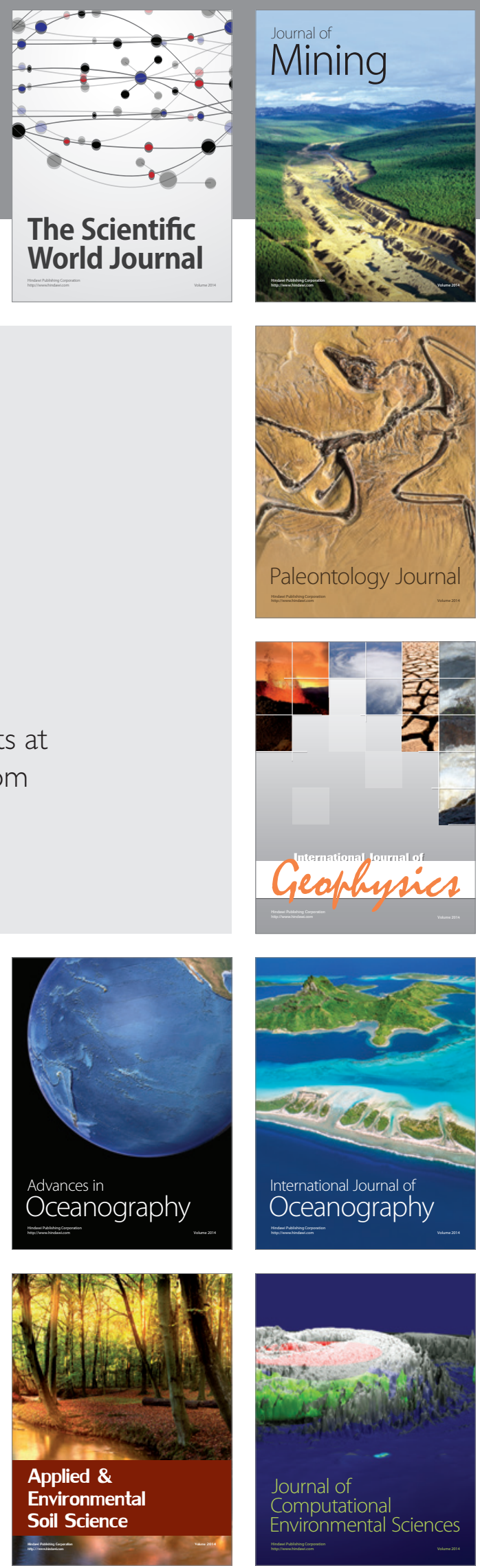